Article

\title{
Pumping Station Design in Water Distribution Networks Considering the Optimal Flow Distribution between Sources and Capital and Operating Costs
}

\author{
Jimmy H. Gutiérrez-Bahamondes ${ }^{1}$, Daniel Mora-Meliá ${ }^{2, *(\mathbb{D})}$, Pedro L. Iglesias-Rey ${ }^{3}$ (D), \\ F. Javier Martínez-Solano ${ }^{3}(\mathbb{D})$ and Yamisleydi Salgueiro ${ }^{4}(\mathbb{D}$
}

1 Doctorado en Sistemas de Ingeniería, Facultad de Ingeniería, Universidad de Talca, Camino Los Niches Km 1 , Curicó 3340000, Chile; jgutierrezb@utalca.cl

2 Departamento de Ingeniería y Gestión de la Construcción, Facultad de Ingeniería, Universidad de Talca, Camino Los Niches Km 1, Curicó 3340000, Chile

3 Departamento de Ingeniería Hidráulica y Medio Ambiente, Universitat Politècnica de València, Camino de Vera S/N, 46022 Valencia, Spain; piglesia@upv.es (P.L.I.-R.); jmsolano@upv.es (F.J.M.-S.)

4 Departamento de Ciencias de la Computación, Facultad de Ingeniería, Universidad de Talca, Camino Los Niches Km 1, Curicó 3340000, Chile; ysalgueiro@utalca.cl

* Correspondence: damora@utalca.cl

check for

updates

Citation: Gutiérrez-Bahamondes, J.H.; Mora-Meliá, D.; Iglesias-Rey, P.L.; Martínez-Solano, F.J.; Salgueiro, Y. Pumping Station Design in Water Distribution Networks Considering the Optimal Flow Distribution between Sources and Capital and Operating Costs. Water 2021, 13, 3098 https://doi.org/10.3390/w13213098

Academic Editor: Wencheng Guo

Received: 4 October 2021

Accepted: 1 November 2021

Published: 3 November 2021

Publisher's Note: MDPI stays neutral with regard to jurisdictional claims in published maps and institutional affiliations.

Copyright: (c) 2021 by the authors. Licensee MDPI, Basel, Switzerland. This article is an open access article distributed under the terms and conditions of the Creative Commons Attribution (CC BY) license (https:// creativecommons.org/licenses/by/ $4.0 /)$.
Abstract: The investment and operating costs of pumping stations in drinking water distribution networks are some of the highest public costs in urban sectors. Generally, these systems are designed based on extreme scenarios. However, in periods of normal operation, extra energy is produced, thereby generating excess costs. To avoid this problem, this work presents a new methodology for the design of pumping stations. The proposed technique is based on the use of a setpoint curve to optimize the operating and investment costs of a station simultaneously. According to this purpose, a novel mathematical optimization model is developed. The solution output by the model includes the selection of the pumps, the dimensions of pipelines, and the optimal flow distribution among all water sources for a given network. To demonstrate the advantages of using this technique, a case study network is presented. A pseudo-genetic algorithm (PGA) is implemented to resolve the optimization model. Finally, the obtained results show that it is possible to determine the full design and operating conditions required to achieve the lowest cost in a multiple pump station network.

Keywords: optimization; water networks; pump station; setpoint curve; pseudo-genetic algorithm

\section{Introduction}

Optimization problems regarding the design and operation of water distribution networks (WDNs) are very complex and important problems that affect the quality of life of all people worldwide [1]. The demand for water increases rapidly with the growth of the world's population. Furthermore, climate change has increased water scarcity [2]. Electric power is one of the dominant costs incurred by water utilities, so reducing energy consumption and conserving the available natural resources (such as water) are some of society's challenges [3]. The design of a cost-effective WDN is not a simple task, and the operational performance of the designed network affects any city budget $[4,5]$. In this regard, pumping stations (PSs) are expensive infrastructures.

Pump operating costs are a key aspect when a network is fed directly from groundwater or does not have a high enough elevation for tanks to be installed [5]. In these cases, the selection of pumps that best adapt to the system head curve is an important step, as doing so reduces excess head pressure [6]. Consequently, the efficient design and operation of PSs could significantly reduce network total costs.

PS design involves the selection of pumps, accessories, and control systems. Traditionally, the selection process is conducted by a catalogue that contains the specifications 
of available pumps. The pumps that provide the required maximum piezometric head are identified, and the selection is based, among other criteria, on energy efficiency. Finally, the number of pumps that make up the station is calculated [7]. Then, PS operation is determined by the on/off status of every pump at each time step and, in the case of variable-speed pumps (VSPs), by modifying the rotational speed based on the readings obtained from the metering devices.

This control system is responsible for adjusting the amount of water pumped according to public demand at every moment [8]. Different approaches for improving PS performance in WDNs have been explored $[1,9,10]$. One of the important problems covered in the literature is pump scheduling optimization. This problem has been widely studied [3,9]. Starting from a completed PS design, pump scheduling can be specified by on/off pump switches during predefined equal time intervals. Traditionally, the objective of such a problem is the minimization of energy consumption costs based on the operation and/or maintenance costs of pumps [3]. These approaches do not allow for any structural changes. Consequently, the obtainable energy savings are restricted by the previous PS design, and insufficient or idle capacity may be generated. Therefore, the investment and operating costs of PSs should be minimized together to achieve a complete solution to the optimization problem [11].

In recent years, mathematical models have been developed to optimize both of the aforementioned general objectives from diverse perspectives. The differences between these models lie in the decision variables used to assemble their object functions and constraints. In this regard, some previous researchers have focused their efforts on optimizing the location of each PS, maximizing energy production [12,13], minimizing losses by installing turbines to recover energy [14], or using the position and setting of a PS, in addition to the working statuses of VSPs, as the decision variables [15]. Other researchers have focused on analyzing the PS capacity to optimize the design and operational costs of stations; the authors of [16] introduced a model with binary variables for each design and operation option available in the face of a small number of demand scenarios. The authors of [11] proposed a new design procedure that considers the variable demand, equivalent flow, and equivalent volume to approximate the annual costs of a given system. The authors of [17] calculated the design cost of an entire network using a robust model based on the variability of the costs of multiple scenarios.

The main problem is that the methods proposed in the literature do not directly link the internal design optimization of PSs with the optimization of the overall operation of the corresponding WDN. Furthermore, the design is formulated while considering extreme operating conditions. To bring these models closer to reality, the design of a PS should evaluate its impact on the entire network, including other PSs, and consider operational implications in the future. To avoid these problems, there are two important stages that must be optimized together. The first stage is to determine the optimal flow and head of a PS. Therefore, the PS should satisfy all demand and pressure requirements. The second stage is to determine the best combination of the internal elements in PSs to achieve these values.

In this context, the authors of [18] minimized the energy consumption of a network after determining that water should be provided by each PS according to the demand curve of the network using a novel optimization model based on a setpoint curve. The heads and flows that must be supplied from each PS are determined, but the design of the PS is not considered. From this viewpoint, considering the results of previous work, the authors of [19] focused their research only on the internal configuration of a PS. The authors proposed an alternative method in which the pumping group selection process includes an estimate of the system operating cost based on the study of different control systems and operation schemes for the pumps before selecting the equipment. To achieve this, investment (pumping equipment, hydraulic installations, and electrical and control equipment) and operational costs are considered. 
This work presents a novel methodology for the optimization of the design of PSs in WDNs. Unlike the models developed in previous works, the proposed model combines the overall optimization process for the distribution of flows and the analysis of the internal components of each PS. It allows for energy and investment costs to be reduced by adjusting the PS capacity according to demand and pump selection at once. For this purpose, the calculation of a setpoint curve and the simulated operation of multiple pump alternatives are combined to create a highly robust optimization model that adjusts the flow rates provided by the pumps according to the given system's demand curves.

Additionally, our work considers the resolution of the optimization model through the implementation of a pseudo-genetic algorithm (PGA) that was presented by [20]. In this regard, evolutionary algorithms have proved to be efficient in handling optimization problems with respect to WDNs, especially when the size of the feasible solution space is extremely large [1,21]. The evaluation of the hydraulic behavior of the resulting network is analyzed using EPANET according to the specifications proposed in [22].

The remainder of the paper is organized as follows: Section 2 describes the proposed methodology. First, the outline, notation, and formulation of the new mathematical model are discussed. Then, the developed methodology is applied to a case study, and an optimization method is implemented. Next, Section 3 provides the results, and a discussion is detailed in Section 4. Finally, the conclusions of the research can be found in Section 5.

\section{Materials and Methods}

\subsection{Model Outline}

In this section, a novel optimization model for designing PSs while considering optimal operating conditions is proposed and mathematically described in detail. Specifically, this model determines the configuration of each PS, including the number of fixed-speed pumps (FSPs) and VSPs, and the pump model according to an available database. The optimization model adjusts the PS design to the optimal distribution of flows, which is calculated during each period within the optimization process.

It is important to highlight that the proposed methodology requires some available data: (a) a WDN model calibrated for different demand conditions, (b) a modular design for the PS, (c) knowledge of the demand patterns, and (d) an existing database to select the correct pump model. The database must include the model, price, and head and efficiency curves for each pump.

Next, a general scheme for the problem to be solved is presented in Figure 1. Specifically, Figure 1a shows a general case with three PSs. During each period, $P_{i}$ distributes $Q_{i}$ of water from the total flow. These flows vary over time according to the demand pattern of the WDN. Figure $1 \mathrm{~b}$ shows the details of the basic modular design of a PS used in this optimization model. A PS consists of several lines in parallel with one pump installed in each. Every pump has two isolation valves and a check valve. There are also two isolation valves at the ends (inlet and outlet) of the PS. The lengths $\mathrm{L}_{1}, \mathrm{~L}_{2}$, and $\mathrm{L}_{3}$ in Figure $1 \mathrm{~b}$ are parameterized as linear combinations of the diameters of the pipes:

$$
\mathrm{L}_{\mathrm{p}}=\lambda_{\mathrm{p}} \cdot \mathrm{ND}_{\mathrm{p}} \forall \mathrm{p} \in\{1,2,3\}
$$

where $\lambda_{p}$ is a parameter defined in each case study, and $\mathrm{ND}_{\mathrm{p}}$ is the nominal diameter (ND) of the corresponding pipe $p$, which is used for defining the diameters of elements such as isolation valves or check valves. 

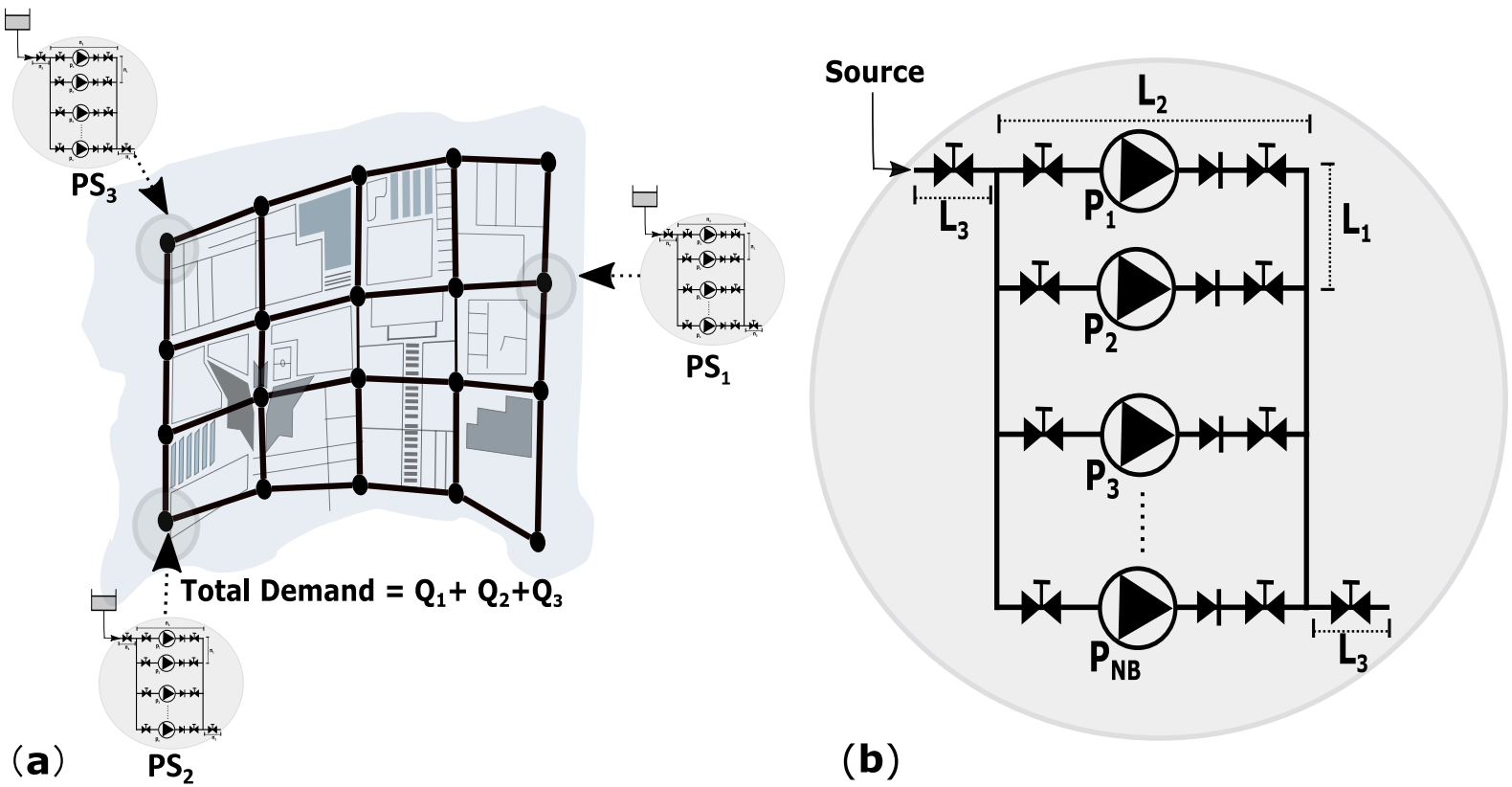

Figure 1. (a) General scheme and (b) PS modular design.

This methodology calculates the optimal flow rates provided by each PS following the methodology presented by [18]. Next, the number of pumps required is determined according to the model. Then, considering the design velocity $\mathrm{V}_{\mathrm{d}}$, the NDs are selected, and finally, the lengths of the pipes are determined using Equation (1). That is, using the basic modular design from Figure $1 \mathrm{~b}$ after the model and number of pumps are determined automatically leads to a specific PS design.

The optimization problem seeks to minimize the capital expenditures (CAPEX) and operating expenses (OPEX) of the general scheme presented in Figure 1 while considering an optimal distribution of flows. First, the decision variables and the mathematical notation of the proposed model are presented. Next, the calculation of OPEX and CAPEX from the decision variables is explained in detail. A case study exemplifies the model implementation in a network with three PSs and a database of pump models. Finally, the optimization method used in this work is briefly presented.

\subsection{Mathematical Notation}

The above problem can be posed as a mathematical optimization model, where the decision variables are related to the distribution of flows among the different sources and the configuration of each PS. On the one hand, $x_{\mathrm{ij}}$ defines the percentage of the flow supplied from PS $i\left(\mathrm{PS}_{\mathrm{i}}\right)$ at each time step $\mathrm{j}$. The parameters $\mathrm{N}_{\mathrm{t}}$ and $\mathrm{N}_{\mathrm{ps}}$ represent the total number of time steps and total number of PSs, respectively; $\mathrm{m}_{\mathrm{i}}$ indicates the number of FSPs; and $b_{i}$ corresponds to the identifier of the pump model to be installed in PS ${ }_{i}$.

Once these values are known, it is possible to calculate the maximum flow for each PS, the number of total pumps $\left(\mathrm{N}_{\mathrm{B}, \mathrm{i}}\right)$, the number of VSPs $\left(\mathrm{n}_{\mathrm{i}}\right)$, and the dimensions of each pipeline $\mathrm{L}_{\mathrm{p}}$. In short, it is possible to fully define the design of the PS.

\subsection{Optimization Model}

The optimization problem seeks to minimize both the CAPEX and the OPEX of the system. The objective function is detailed in Equations (2) and (3):

$$
\begin{gathered}
\mathrm{F}=\mathrm{F}_{\mathrm{a}} \cdot \text { CAPEX }+ \text { OPEX } \\
\mathrm{F}_{\mathrm{a}}=\frac{\mathrm{r} \cdot(1+\mathrm{r})^{\mathrm{N}_{\mathrm{p}}}}{(1+\mathrm{r})^{\mathrm{N}_{\mathrm{p}}}-1}
\end{gathered}
$$


where F represents the total annualized cost of the project. To calculate the loss of value of the assets over the useful life of the project, CAPEX is amortized by the factor $\mathrm{F}_{\mathrm{a}}$ applying an interest rate $r$ during $N_{p}$ periods. OPEX represents the total operational expenses throughout the life of the project.

Obviously, the optimization model is restricted by continuity and momentum equations and by minimum head requirements in the demand nodes. Additionally, the model is constrained by Equations (4) and (5). These equations guarantee that the total flow supplied by the PS is equal to the flow demanded during each period.

$$
\begin{gathered}
x_{i, j} \geq 0 \forall i, j \\
\sum_{i=1}^{N_{p s}} x_{i, j}=1 \forall j
\end{gathered}
$$

The optimization model calculates the CAPEX and OPEX from the values of the decision variables in each iteration of the algorithm. Figure 2 shows a flowchart of the complete model.

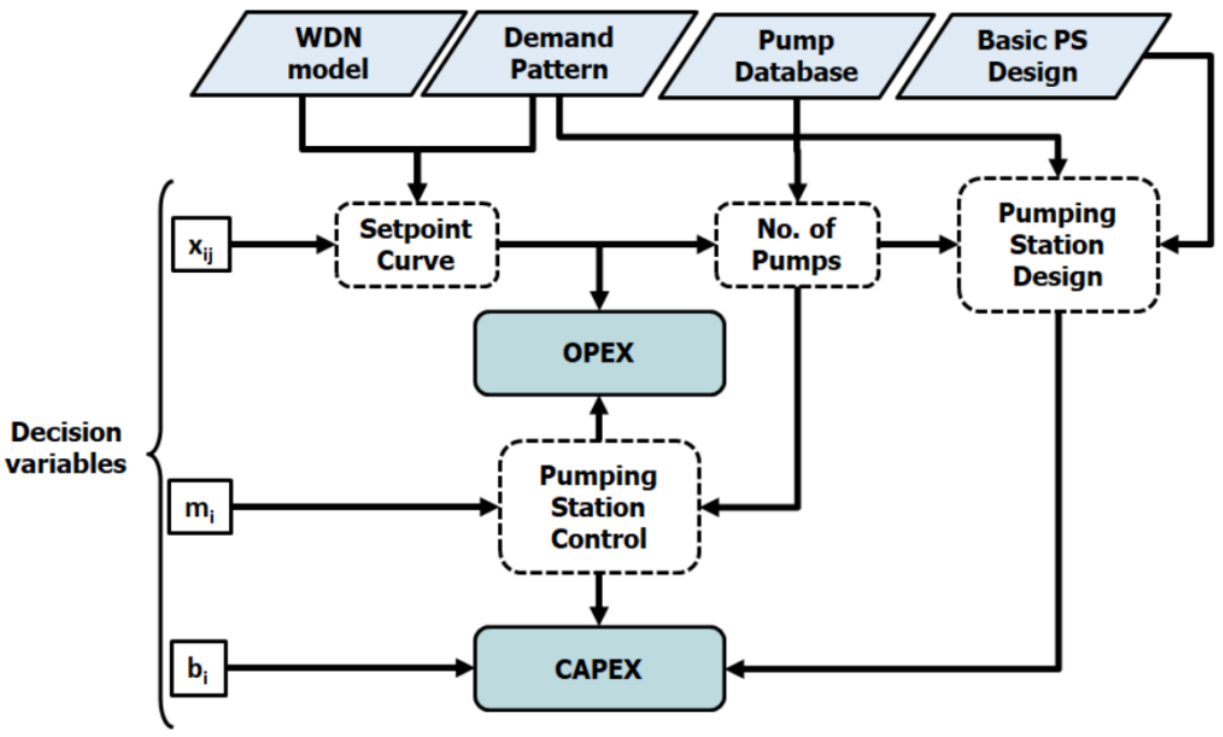

Figure 2. Calculation of OPEX and CAPEX.

Figure 2 shows how the decision variables and the model input requirements are related. The dashed lines represent four intermediate steps required to calculate the CAPEX and OPEX. After solving the mathematical model, it is possible to determine the setpoint curve for each PS, the complete PS design, the dimensions of all pipes, the number of pumps, the respective models, and the PS control systems.

This methodology can be described through three steps. The first step determines the setpoint curve using the methodology proposed by [18]. The setpoint curve represents the minimum head required at each PS for a certain flow distribution. From the distribution of flows $\mathrm{x}_{\mathrm{ij}}$, considering the mathematical model of the network and the demand pattern, it is possible to calculate the vectors of the head $\mathrm{HS}_{\mathrm{ij}}$ and flow $\mathrm{QS}_{\mathrm{ij}}$ that must be supplied by $\mathrm{PS}_{\mathrm{i}}$ at time step $\mathrm{j}$. Then, the control system is adjusted in such a way that the output of the PSs is always equal to the $\mathrm{HS}_{\mathrm{ij}}$ and $\mathrm{QS}_{\mathrm{ij}}$ values of the setpoint curve. Therefore, it is possible to guarantee compliance with the minimum pressure restrictions for all nodes of the network.

The second step calculates the total number of pumps $\mathrm{N}_{\mathrm{B}, \mathrm{i}}$ for each $\mathrm{PS}_{\mathrm{i}}$. First, the maximum head $\mathrm{H}_{\mathrm{i}, \max }$ and flow $\mathrm{Q}_{\mathrm{i}, \max }$ are determined from the setpoint curve. Then, 
Equation (6) is used to calculate the flow rate $Q_{i, b}$ supplied by a single pump for the head $\mathrm{H}_{\mathrm{i}, \mathrm{max}}$.

$$
\mathrm{H}_{\mathrm{b}_{\mathrm{i}}}=\mathrm{H}_{0, \mathrm{~b}_{\mathrm{i}}}-\mathrm{A}_{\mathrm{b}_{\mathrm{i}}} \cdot \mathrm{Q}^{2} \rightarrow \mathrm{Q}_{1, \mathrm{~b}}=\sqrt{\frac{\mathrm{H}_{0, \mathrm{~b}_{\mathrm{i}}}-\mathrm{H}_{\mathrm{i}, \max }}{\mathrm{A}_{\mathrm{b}_{\mathrm{i}}}}}
$$

In the previous equation, note that the parameters $\mathrm{H}_{0, \mathrm{bi}}$ and $\mathrm{A}_{\mathrm{b}, \mathrm{i}}$ are determined from the characteristic curve of $b_{i}$. The number of pumps in $P S_{i}$ is obtained by Equation (7).

$$
\mathrm{N}_{\mathrm{B}, \mathrm{i}}=\left(\frac{\mathrm{Q}_{\mathrm{i}, \max }}{\mathrm{Q}_{1, \mathrm{~b}}}\right),
$$

where the result $\mathrm{N}_{\mathrm{B}, \mathrm{i}}$ is rounded up to the next integer. Finally, the number of VSPs $\left(\mathrm{n}_{\mathrm{i}}\right)$ can be determined using Equation (8). There must always be at least one VSP.

$$
\mathrm{n}_{\mathrm{i}}=\mathrm{N}_{\mathrm{B}, \mathrm{i}}-\mathrm{m}_{\mathrm{i}}
$$

The third step defines the PS design. A PS is completely defined when the maximum demand of the PS, the number of pumps, and the pump model selected in the database are known. Then, it is possible to calculate both the CAPEX and OPEX.

The CAPEX is calculated according to Equation (9), representing the total investment costs for each PS.

$$
\mathrm{C}_{\text {CAPEX }}=\mathrm{N}_{\mathrm{B}} \cdot \mathrm{C}_{\text {pump }}+\mathrm{n} \cdot \mathrm{C}_{\mathrm{inv}}+\mathrm{C}_{\text {facility }}+\mathrm{C}_{\text {control }}
$$

According to [19], these values can be calculated as follows. The first term ( $\left.C_{\text {pump }}\right)$ represents the cost of a pump according to Equation (10), where $\mathrm{CP}_{0}$ and $\mathrm{CP}_{1}$ depend on the case study.

$$
\mathrm{C}_{\text {pump }}=\mathrm{CP}_{0} \cdot(\mathrm{Q} \cdot \mathrm{H})^{\mathrm{CP}_{1}}
$$

The second term of Equation (9) constitutes the cost of the frequency inverter $\left(C_{i n v}\right)$ for each VSP. The third term $\left(C_{\text {facility }}\right)$ is explained in Equation (11), which considers pipes and accessories.

$$
C_{\text {facility }}=\left(2 N_{B}+2\right) \cdot C_{S V}+N_{B} \cdot C_{C V}+\sum_{i=1}^{n_{T}} C_{T}+\sum_{i=1}^{n_{e}} C_{\text {elbow }}+\sum_{i=1}^{n_{p}} C_{\text {pipe, },} \cdot l_{i}
$$

where for each PS, NB is the number of pumps, $n_{T}$ is the number of union tees, $n_{e}$ is the number of elbows, $n_{p}$ is the number of pipes, and $l_{i}$ is the length of pipe $i$.

Specifically, the previous equation considers the costs of isolation valves $\left(\mathrm{C}_{\mathrm{SV}}\right)$, check valves $\left(\mathrm{C}_{\mathrm{CV}}\right)$, pipes $\left(\mathrm{C}_{\text {pipe }}\right)$, elbows $\left(\mathrm{C}_{\text {elbow }}\right)$, and union tees $\left(\mathrm{C}_{\mathrm{T}}\right)$.

Finally, the fourth term represents all control components $\left(\mathrm{C}_{\text {control }}\right)$ according to Equation (12). Among these components, a pressure transducer $\left(\mathrm{C}_{\text {pressure }}\right)$, flowmeter $\left(\mathrm{C}_{\text {flowmeter }}\right)$, and programmable logic controller $\left(\mathrm{C}_{\mathrm{PLC}}\right)$ are included.

$$
\mathrm{C}_{\text {control }}=\mathrm{C}_{\text {pressure }}+\mathrm{C}_{\text {flowmeter }}+\mathrm{C}_{\mathrm{PLC}}
$$

where $\mathrm{C}_{\text {pressure }}$ and $\mathrm{C}_{\mathrm{PLC}}$ correspond to the acquisition prices of the pressure switch and programmable logic controller, respectively.

The $C_{\text {inv }}$ and $C_{\text {facility }}$ values can be expressed as second-degree polynomial curves as functions of the pump power $\mathrm{P}(\mathrm{kW})$. Similarly, $\mathrm{C}_{\mathrm{SV}}, \mathrm{C}_{\mathrm{CV}}, \mathrm{C}_{\text {pipe, }}, \mathrm{C}_{\text {elbow }}, \mathrm{C}_{\mathrm{T}}$, and $\mathrm{C}_{\text {flowmeter }}$ are functions of the ND and fit to second-degree polynomial curves. All coefficients of the polynomials incorporated in the previous equations depend on the case study.

Finally, to calculate the OPEX, the cost of the total electrical power consumed by all pumps running in the WDN during time step $\mathrm{N}_{\mathrm{t}}$ is determined using Equation (13). 


$$
\text { OPEX }=\sum_{j=1}^{N_{t}}\left\{\sum_{i=1}^{N_{p s}}\left[\left(\sum_{k=1}^{m_{i, j}} \frac{\gamma \cdot\left(H_{0, i}-A_{i} \cdot Q_{i, j k}^{2}\right)}{\left(E_{i}-F_{i} \cdot Q_{i, j, k}\right)}+\sum_{k=1}^{n_{j, i}} \frac{\gamma \cdot\left(H_{o, i} \cdot \alpha_{i, j, k}-A_{i} \cdot Q_{i, j k}^{2}\right)}{\left(\frac{E_{i}}{\alpha_{i, j, k}}-\frac{F_{i}}{\alpha_{i, j, k}} \cdot Q_{i, j, k}\right)}\right) \cdot p_{i, j}\right] \cdot t_{j}\right\}
$$

where for each $\mathrm{PS}_{\mathrm{i}}$, the parameters $\mathrm{H}_{0, \mathrm{i}}, \mathrm{Ai}, \mathrm{E}_{\mathrm{i}}$, and $\mathrm{F}_{\mathrm{i}}$ are the characteristic coefficients of the pump head and the performance curve and are extracted from an existing database depending on the pump model; $\mathrm{Q}_{\mathrm{i}, \mathrm{j}, \mathrm{k}}$ represents the discharge of pump $\mathrm{k}$ during time step $\mathrm{j}$ in PS $\mathrm{i} ; \mathrm{p}_{\mathrm{i}, \mathrm{j}}$ is the energy cost, $\gamma$ is the specific gravity of water, $\Delta t_{j}$ is the discretization interval of the optimization period, and the numbers of FSPs and VSPs running at time step $\mathrm{j}$ are represented by $\mathrm{m}_{\mathrm{i}, \mathrm{j}}$ and $\mathrm{n}_{\mathrm{i}, \mathrm{j}}$, respectively. These values depend on the selected pump model and the system selected to control the operation point. In this work, pumps are controlled by adjusting their heads to the setpoint curve $\mathrm{HS}_{\mathrm{i}, \mathrm{j}}$. To achieve this, the parameter $\alpha$ is calculated according to Equation (14).

$$
\alpha=\sqrt{\frac{H S_{i, j}+A_{i}\left(\frac{Q_{i, j, k}}{N_{B, i}}\right)^{2}}{H_{0, i}}}
$$

\subsection{Case Study}

To apply the methodology described above, one case study was conducted. Figure 3 shows the topology of a new WDN called the MTF network.

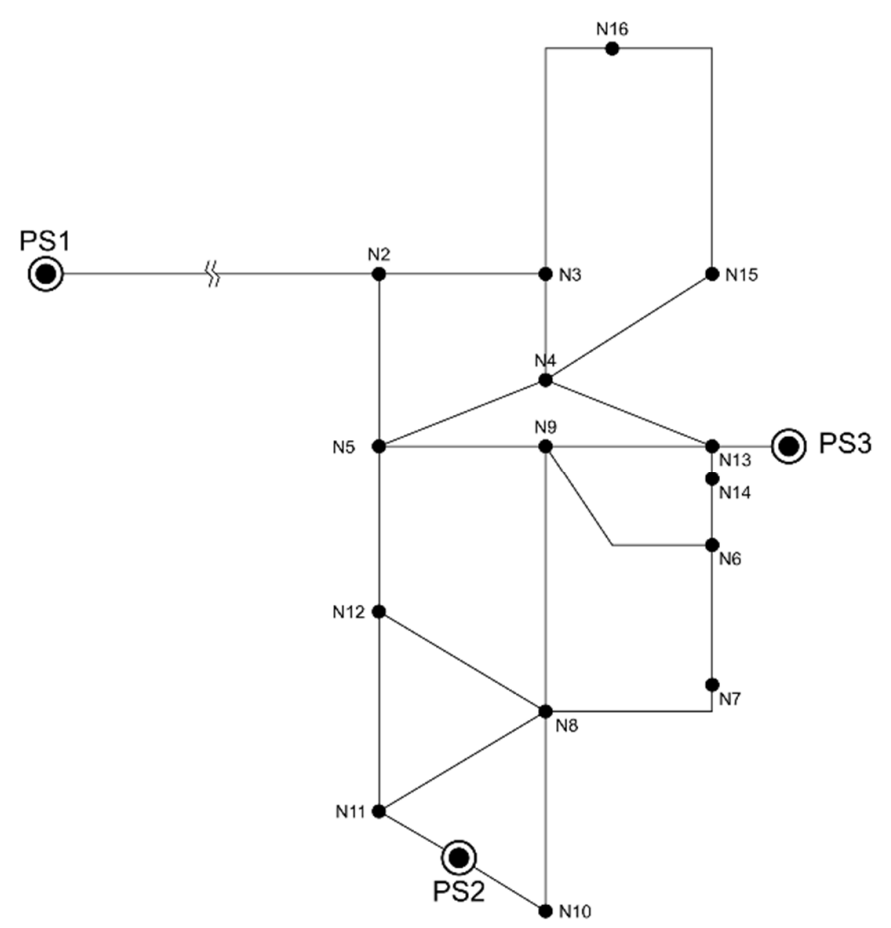

Figure 3. MTF network.

The MTF network has 3 PSs (PS1, PS2, and PS3), 15 consumption nodes, and 25 pipes. A hydraulic analysis was carried out for one day, and the time was discretized in periods of one hour. The minimum pressure at the nodes is $20 \mathrm{~m}$, the demanded average flow rate is $100 \mathrm{~L} / \mathrm{s}$, and the roughness coefficient is 0.1 . Information about the nodes and pipelines is detailed in Tables 1 and 2, respectively. To calculate OPEX, Table 3 presents the hourly electricity tariff for each PS in the MTF network. 
Table 1. Case study network: node information.

\begin{tabular}{cccccc}
\hline ID & Elevation $(\mathbf{m})$ & Base Demand (L/s) & ID & Elevation $(\mathbf{m})$ & Base Demand (L/s) \\
\hline N2 & 8 & 5 & N11 & 7 & 5 \\
N3 & 8 & 4 & N12 & 7 & 10 \\
N4 & 5 & 3 & N13 & 5 & 5 \\
N5 & 8 & 4 & N14 & 4 & 2 \\
N6 & 4 & 3 & N15 & 3 & 10 \\
N7 & 2 & 8 & N16 & 3 & 15 \\
N8 & 5 & 7 & PS2 & 4 & - \\
N9 & 6 & 10 & PS3 & 0 & - \\
N10 & 2 & 9 & PS1 & 23 & - \\
\hline
\end{tabular}

Table 2. Case study network: pipeline information.

\begin{tabular}{cccccccccc}
\hline Pipe ID & Node 1 & Node 2 & Length $(\mathbf{m})$ & Diam. $(\mathbf{m m})$ & Pipe ID & Node 1 & Node 2 & Length (m) & Diam. $(\mathbf{m m})$ \\
\hline 1 & N2 & N3 & 200 & 200 & 13 & N12 & N8 & 300 & 100 \\
2 & N3 & N4 & 150 & 150 & 14 & N12 & N5 & 250 & 150 \\
3 & N4 & N5 & 150 & 150 & 15 & N9 & N13 & 250 & 100 \\
4 & N5 & N2 & 200 & 250 & 16 & N6 & N14 & 100 & 98 \\
5 & N6 & N7 & 200 & 150 & 17 & N4 & N13 & 200 \\
6 & N8 & N9 & 400 & 100 & 18 & N4 & N15 & 300 & 100 \\
7 & N7 & N8 & 300 & 100 & 19 & N15 & N16 & 500 & 100 \\
8 & N9 & N6 & 300 & 100 & 20 & N3 & N16 & 400 & 150 \\
9 & N9 & N5 & 250 & 100 & 21 & PS1 & N2 & 1500 & 300 \\
10 & N8 & N10 & 300 & 100 & 22 & PS2 & N11 & 125 & 100 \\
11 & N11 & N12 & 300 & 100 & 23 & N13 & N14 & 52 & 150 \\
12 & N10 & PS2 & 125 & 100 & 24 & N13 & PS3 & 100 & 100 \\
\hline
\end{tabular}

Table 3. Electricity for the case study $(€ / \mathrm{kWh})$.

\begin{tabular}{cccc}
\hline Time (h) & PS1 & PS2 & PS3 \\
\hline $1-8$ & 0.094 & 0.092 & 0.09 \\
$9-18$ & 0.133 & 0.131 & 0.129 \\
$19-22$ & 0.166 & 0.164 & 0.162 \\
$23-24$ & 0.133 & 0.131 & 0.129 \\
\hline
\end{tabular}

In Table 1, the base demand represents the average or nominal demand for water at the junction. A time pattern is used to characterize time variation in demand, providing multipliers that are applied to the base demand to determine actual demand in a given time period. The demand patterns for the $24 \mathrm{~h}$ of a day are presented in Figure 4.

To perform the optimization process, a database with 67 pump models was used. The maximum flow rate of the pumps in the database varied between $9 \mathrm{~L} / \mathrm{s}$ and $50.7 \mathrm{~L} / \mathrm{s}$. The maximum head fluctuated between $15.8 \mathrm{~m}$ and $105 \mathrm{~m}$, and the maximum efficiency was in the range of $39 \%$ to $84 \%$. The annualized costs of these models were calculated using an interest rate of $5 \%$ per year and a projection time of 20 years, as indicated by [7]. This led to an amortization factor $\mathrm{F}_{\mathrm{a}}=7.92 \%$. To calculate the length of the pipes $\left(\mathrm{L}_{\mathrm{p}}\right)$, values of 5 , 30 , and 10 were used for $\lambda_{1}, \lambda_{2}$, and $\lambda_{3}$, respectively.

To calculate CAPEX, the $\mathrm{CP}_{0}$ and $\mathrm{CP}_{1}$ values from Equation (10) are 142.88 and 0.5437, respectively, for efficiency values less than or equal to $65 \%$ or 203.14 and 0.6115 otherwise. The coefficients of the polynomial equations used to calculate Equation (9) are expressed in the format $f(x)=a x^{2}+b x+c$. The independent variable $(x)$ can be represented by P or ND. The values of coefficients $a, b$, and $c$ are shown in Table 4 . These values were determined by [19]. In the case of the pressure transducer $\left(C_{\text {pressure }}\right)$ and programmable logic controller $\left(\mathrm{C}_{\mathrm{PLC}}\right)$, they assume a constant price of 570 and 372.44 EUR, respectively. Furthermore, 
the flowmeter is always installed in outlet pipe $\mathrm{L}_{3}$ (Figure $1 \mathrm{~b}$ ) and therefore has the same diameter as that pipe.

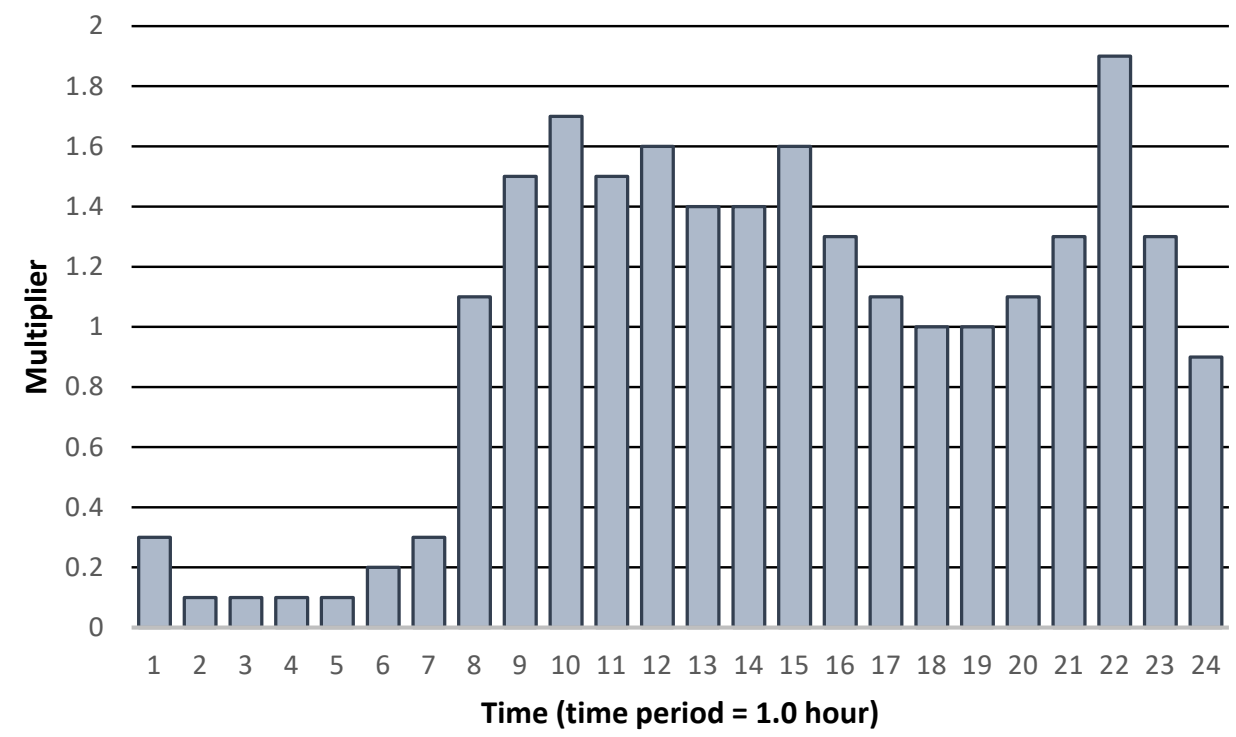

Figure 4. Demand pattern for the MTF network.

Table 4. Case study coefficients for calculating CAPEX equations.

\begin{tabular}{ccccc}
\hline $\mathbf{f}(\mathbf{x})$ & $\mathbf{x}$ & $\mathbf{a}$ & $\mathbf{b}$ & $\mathbf{c}$ \\
\hline $\mathrm{C}_{\text {inv }}$ & $\mathrm{P}(\mathrm{W})$ & -0.603 & 116.08 & 168.19 \\
$\mathrm{C}_{\mathrm{SV}}$ & & 0.01 & 1.53 & 11.82 \\
$\mathrm{C}_{\mathrm{CV}}$ & & 0.006 & 0.25 & 14.55 \\
$\mathrm{C}_{\text {pipe }}$ & $\mathrm{ND}(\mathrm{mm})$ & 0.0004 & -0.15 & 8.01 \\
$\mathrm{C}_{\text {elbow }}$ & & 0.02 & -4.23 & 269.49 \\
$\mathrm{C}_{\mathrm{T}}$ & & 0.001 & -1.74 & 144.24 \\
$\mathrm{C}_{\text {flowmeter }}$ & & 0.051 & -7.91 & 716.64 \\
\hline
\end{tabular}

\subsection{Optimization Method}

The proposed optimization model requires the use of a computational method to solve a given problem. The solution space of the problem to be solved in this case study is equal to $10^{104}$ possible combinations, and the objective function is not linear. Therefore, the use of traditional deterministic optimization methodologies is not possible. Because of the huge space of solutions and the complexity of the objective function, it is advisable to use a heuristic method [5]. In the literature, there are many available algorithms that can be adapted to solve the proposed mathematical model. In this case, the meta-heuristic algorithm chosen is a pseudo-genetic algorithm (PGA) developed by the authors, whose details and particularities can be found in [20].

Unlike the traditional version of the genetic algorithm, the PGA is based on the integer coding of its solutions. The software was implemented in the Java language following the specification of [22]. This system can conduct massive simulations and is integrated with the hydraulic network solver EPANET using the programmer's toolkit [23].

Different parameters guide the search process of the algorithm, so the obtained results are sensitive to the values of these parameters. The main parameters of the proposed PGA are the population size $(\mathrm{P})$, crossover frequency $(\mathrm{Pc})$, and mutation frequency $(\mathrm{Pm})$. We have adopted the optimal parameter calibration range obtained in previous works for the PGA [22,24-26]. To ensure a minimum level of statistical confidence of the results, 500 experiments were performed and analyzed. 


\section{Results}

Through the proposed methodology, the designs and operations of the PSs in the case study were optimized. Table 5 details the dimensions of $\mathrm{ND}_{1}, \mathrm{ND}_{2}$, and $\mathrm{ND}_{3}$ and the lengths of pipes $L_{1}, L_{2}$, and $L_{3}$ according to the modular design presented in Figure $1 b$. Furthermore, Table 5 shows the number of FSPs and VSPs $\left(m_{i}, n_{i}\right)$ and the characteristic and efficiency curve coefficients $\mathrm{H}_{0}, \mathrm{~A}, \mathrm{E}$, and $\mathrm{F}$. In addition, the last row displays the selected model pump from the database.

Table 5. Pump station designs for the case study.

\begin{tabular}{ccccc}
\hline & & PS $_{\mathbf{1}}$ & PS $_{\mathbf{2}}$ & PS $_{\mathbf{3}}$ \\
\hline \multirow{3}{*}{$(\mathrm{mm})$} & $\mathrm{ND}_{1}$ & 300 & 200 & 150 \\
& $\mathrm{ND}_{2}$ & 125 & 125 & 150 \\
& $\mathrm{ND}_{3}$ & 300 & 200 & 150 \\
& $\mathrm{~L}_{1}$ & 1.5 & 1 & 0.75 \\
& $\mathrm{~L}_{2}$ & 3.75 & 3.75 & 4.5 \\
& $\mathrm{~L}_{3}$ & 3 & 2 & 1.5 \\
$\mathrm{~m}_{\mathrm{i}}$ & 0 & 0 & 0 \\
$\mathrm{n}_{\mathrm{i}}$ & 5 & 2 & 1 \\
& $\mathrm{H}_{0}$ & 38.0800 & 53.7000 & 104.9800 \\
$\mathrm{~A}$ & -0.02094 & -0.06002 & -0.04438 \\
& $\mathrm{E}$ & 0.07130 & 0.10899 & 0.05182 \\
& $\mathrm{~F}$ & 0.00167 & 0.00364 & 0.00107 \\
& Model Id & GNI 50-16/10 & GNI 100-20/50 & GNI 50-26/40 \\
\hline
\end{tabular}

Figure 5 details the flow $\mathrm{QS}_{\mathrm{ij}}$ that must be supplied by $\mathrm{PS}_{\mathrm{i}}$ at time step $\mathrm{j}$ according to the calculated setpoint curve. The pattern of daily consumption is represented by a dotted line. Additionally, the number of active pumps is included in the middle of each bar of the graph. If the color associated with a PS does not appear in a bar, it means that it is not necessary to turn on any pumps during that period. The results show that PS1 supplies a large portion of the total flow. However, depending on the required flow and head calculated, the mathematical model determines the optimal combination of active pumps and its speed of rotation to be able to supply exactly the demand of each period.

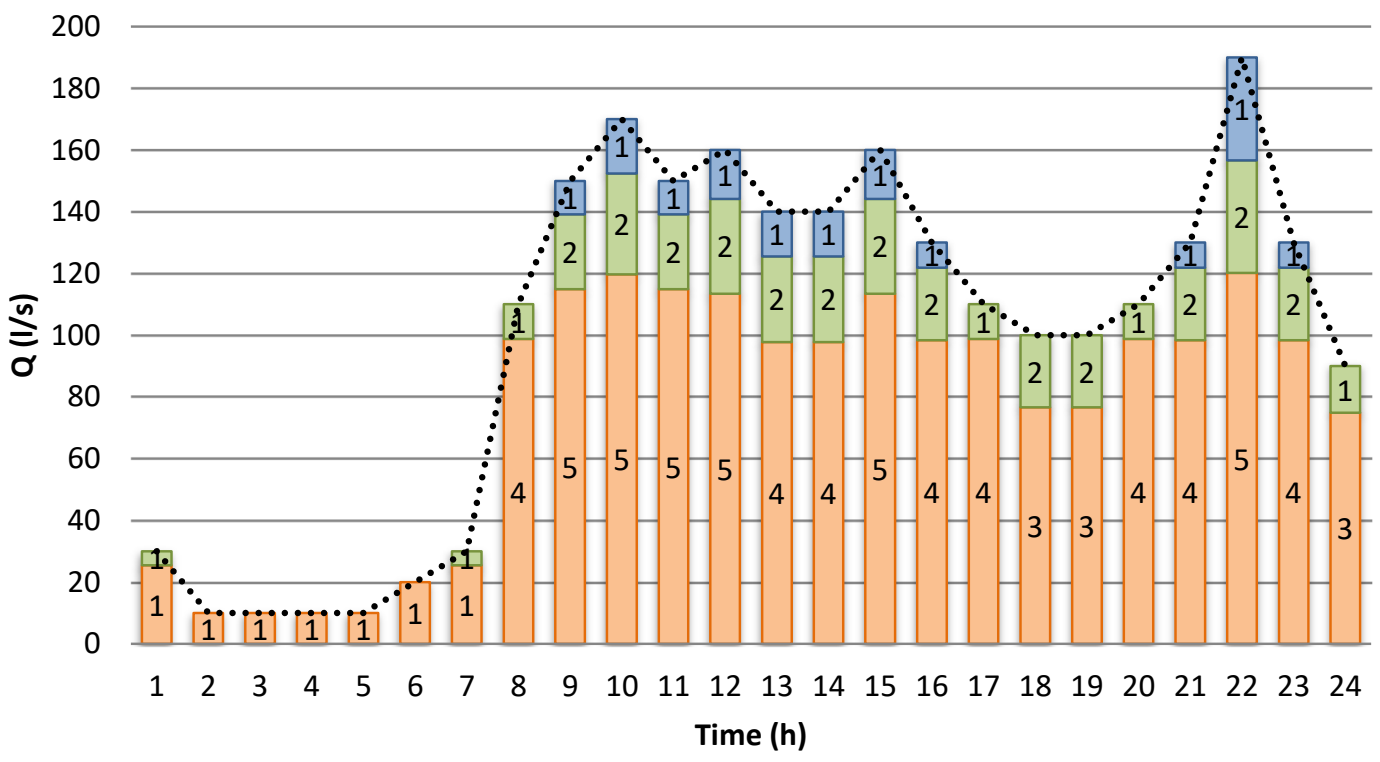

$\square$ PS1 $\square$ PS2 $\square$ PS3 $\quad$....... Water demand network

Figure 5. Optimized case study operations. 
To clarify, Table 6 shows the details of the rotation speed fraction of the pumps $(\alpha)$, used to calculate the efficiency $(\eta)$ according to Equation (15).

$$
\eta=E \frac{Q}{\alpha \cdot n}-F\left(\frac{Q}{\alpha \cdot n}\right)^{2}
$$

where $\mathrm{Q}$ is the flow driven by the PS, $\mathrm{n}$ is the number of pumps, and $\mathrm{E}$ and $\mathrm{F}$ are the efficiency curve coefficients. It is important to highlight that, despite the loss of efficiency of the pumps, the level of power consumption in the PSs is the minimum to ensure that all nodes of the network reach the minimum pressure of the network $(20 \mathrm{~m})$. The flows $\mathrm{Q}_{\mathrm{ij}}$ and heads $\mathrm{HS}_{\mathrm{ij}}$ are also presented for each $\mathrm{PS}_{\mathrm{i}}$ during a $24 \mathrm{~h}$ period.

Table 6. PS designs for the case study.

\begin{tabular}{|c|c|c|c|c|c|c|c|c|c|c|c|c|}
\hline \multirow[b]{2}{*}{$T(h)$} & \multicolumn{4}{|c|}{ PS1 } & \multicolumn{4}{|c|}{ PS2 } & \multicolumn{4}{|c|}{ PS3 } \\
\hline & $\alpha$ & $\eta$ & $\mathrm{QS}(\mathrm{L} / \mathrm{s})$ & HS(m) & $\alpha$ & $\eta$ & $\mathrm{QS}(\mathrm{L} / \mathrm{s})$ & HS(m) & $\alpha$ & $\eta$ & QS(L/s) & HS(m) \\
\hline 1 & 0.714 & 0.413 & 25.500 & 5.773 & 0.629 & 0.593 & 4.500 & 20.020 & - & - & - & - \\
\hline 2 & 0.436 & 0.756 & 10.000 & 5.137 & - & - & - & - & - & - & - & - \\
\hline 3 & 0.436 & 0.756 & 10.000 & 5.137 & - & - & - & - & - & - & - & - \\
\hline 4 & 0.436 & 0.756 & 10.000 & 5.137 & - & - & - & - & - & - & - & - \\
\hline 5 & 0.436 & 0.756 & 10.000 & 5.137 & - & - & - & - & - & - & - & - \\
\hline 6 & 0.603 & 0.526 & 20.000 & 5.483 & - & - & - & - & - & - & - & - \\
\hline 7 & 0.714 & 0.413 & 25.500 & 5.773 & 0.629 & 0.593 & 4.500 & 20.020 & - & - & - & - \\
\hline 8 & 0.863 & 0.671 & 98.780 & 15.564 & 0.706 & 0.812 & 11.220 & 19.231 & - & - & - & - \\
\hline 9 & 0.916 & 0.736 & 114.900 & 20.888 & 0.782 & 0.814 & 24.300 & 24.011 & 0.591 & 0.591 & 10.800 & 31.436 \\
\hline 10 & 0.972 & 0.741 & 119.765 & 23.924 & 0.921 & 0.787 & 32.640 & 29.544 & 0.694 & 0.629 & 17.595 & 36.784 \\
\hline 11 & 0.916 & 0.736 & 114.900 & 20.888 & 0.782 & 0.814 & 24.300 & 24.011 & 0.591 & 0.591 & 10.800 & 31.436 \\
\hline 12 & 0.920 & 0.741 & 113.440 & 21.460 & 0.885 & 0.794 & 30.720 & 27.944 & 0.662 & 0.630 & 15.840 & 34.838 \\
\hline 13 & 0.870 & 0.683 & 97.790 & 16.301 & 0.830 & 0.804 & 27.720 & 25.506 & 0.631 & 0.628 & 14.490 & 32.491 \\
\hline 14 & 0.870 & 0.683 & 97.790 & 16.301 & 0.830 & 0.804 & 27.720 & 25.506 & 0.631 & 0.628 & 14.490 & 32.491 \\
\hline 15 & 0.920 & 0.741 & 113.440 & 21.460 & 0.885 & 0.794 & 30.720 & 27.944 & 0.662 & 0.630 & 15.840 & 34.838 \\
\hline 16 & 0.863 & 0.673 & 98.410 & 15.662 & 0.761 & 0.814 & 23.400 & 22.903 & 0.552 & 0.534 & 8.190 & 29.053 \\
\hline 17 & 0.863 & 0.671 & 98.780 & 15.564 & 0.706 & 0.812 & 11.220 & 19.231 & - & - & - & - \\
\hline 18 & 0.809 & 0.584 & 76.600 & 11.240 & 0.773 & 0.815 & 23.400 & 23.909 & - & - & - & - \\
\hline 19 & 0.809 & 0.584 & 76.600 & 11.240 & 0.773 & 0.815 & 23.400 & 23.909 & - & - & - & - \\
\hline 20 & 0.863 & 0.671 & 98.780 & 15.564 & 0.706 & 0.812 & 11.220 & 19.231 & - & - & - & - \\
\hline 21 & 0.863 & 0.673 & 98.410 & 15.662 & 0.761 & 0.814 & 23.400 & 22.903 & 0.552 & 0.534 & 8.190 & 29.053 \\
\hline 22 & 1.000 & 0.748 & 120.175 & 25.942 & 0.992 & 0.772 & 36.480 & 32.888 & 0.986 & 0.534 & 33.345 & 52.681 \\
\hline 23 & 0.863 & 0.673 & 98.410 & 15.662 & 0.761 & 0.814 & 23.400 & 22.903 & 0.552 & 0.534 & 8.190 & 29.053 \\
\hline 24 & 0.793 & 0.588 & 74.880 & 10.901 & 0.800 & 0.758 & 15.120 & 20.663 & - & - & - & - \\
\hline
\end{tabular}

Table 7 details the CAPEX and OPEX values for the best solution found. First, on the dotted line, all CAPEX terms of Equation (9) are exposed. The OPEX costs are shown according to Equation (13). The last row details the annualized costs according to Equation (2) for each PS. In this case study, the calculated coefficient $F_{a}$ is 0.0791 . The total annualized cost is highlighted in the lower right corner of the table.

Table 7. Cost details of the obtained solution.

\begin{tabular}{cccccc}
\hline & & PS1 & PS2 & PS3 & Total \\
\hline \multirow{6}{*}{ CAPEX } & $C_{\text {pump }}$ & $€ 51,225$ & $€ 20,357$ & $€ 8698$ & $€ 80,280$ \\
& $C_{\text {inv }}$ & $€ 5024$ & $€ 7274$ & $€ 3108$ & $€ 15,406$ \\
& $C_{\text {Facility }}$ & $€ 16,928$ & $€ 4809$ & $€ 2547$ & $€ 24,284$ \\
Fa x CAPEX + OPEX & C Control & $€ 3297$ & $€ 1543$ & $€ 1048$ & $€ 5887$ \\
& OPEX & $€ 26,020$ & $€ 8441$ & $€ 5798$ & $€ 40,292$ \\
\hline
\end{tabular}


Finally, the curve on Figure 6 shows the evolution of objective function value during the process optimization. The best solution is marked by points, while the shaded area represents the represents the solution intervals for the 500 experiments.

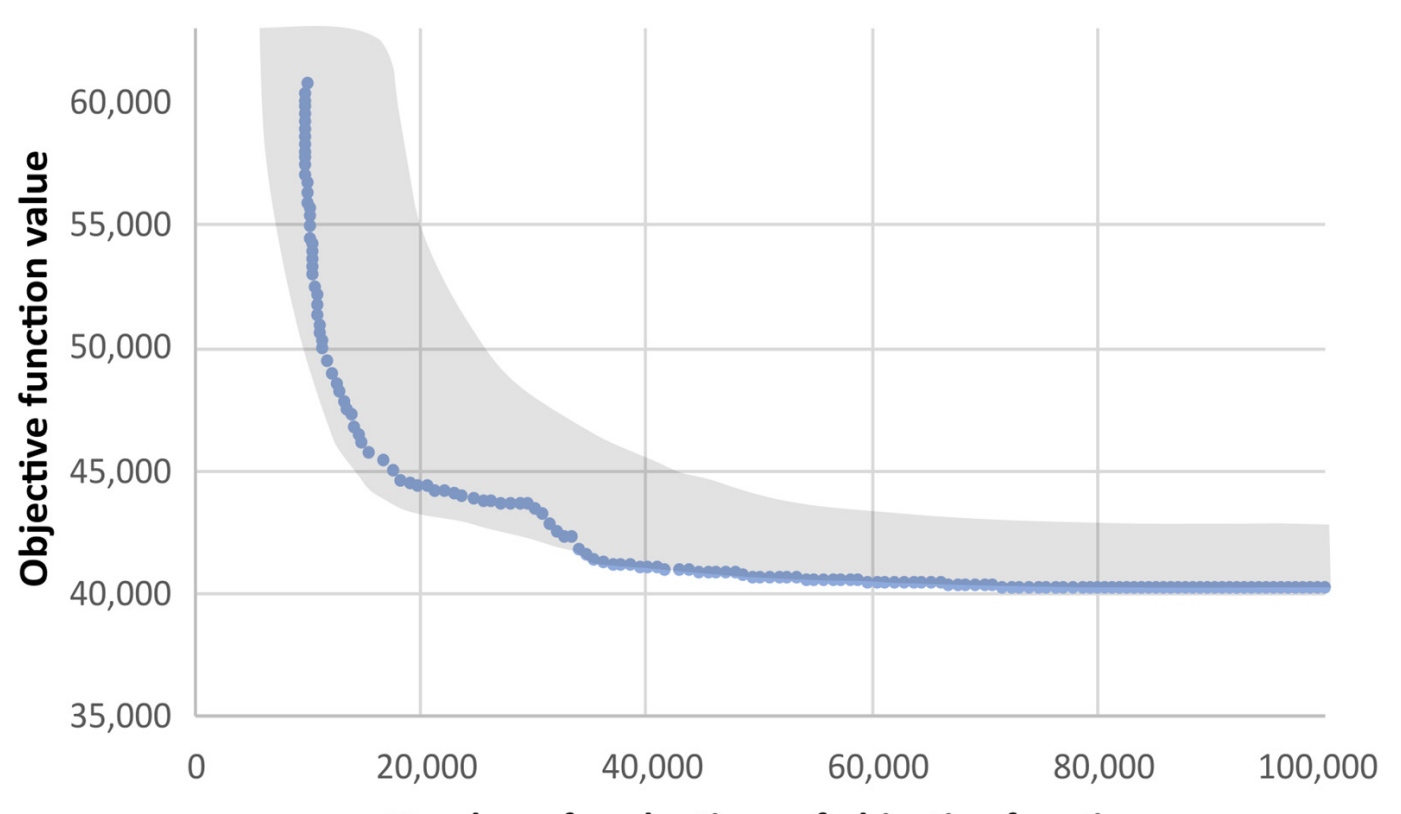

Number of evaluations of objective function

Figure 6. Optimization process evolution.

\section{Discussion}

The application of the new methodology aims to find the optimal economic design of PS1, PS2, and PS3, minimizing the sum of CAPEX and OPEX. In addition to the complete design of the PSs, the solution determines the operational conditions of each pump for each time step of the day.

The calculation of the setpoint curve is the key to the methodology presented. By delivering exactly the energy established by the setpoint curve, it is possible to ensure compliance with the predefined head requirements using the minimum amount of energy. This information is then used to design all PSs at once.

The traditional design method takes only the highest point of demand [7]. Consequently, the distribution of flows is considered an isolated optimization stage and does not consider the effects of the operations during the rest of the daily periods. Therefore, the process of finding the lowest cost solution is complex and ineffective. In contrast, the new mathematical model considers the possible energy consumption of WDN operations over the analysis time for each possible design.

In the case study, if only the period with the highest demand is considered (time $=22 \mathrm{~h}$ ), there are many design combinations for each PS that would allow for the flow rates and heads to be achieved. However, optimizing total costs is not successful. For example, if the pump model selected for PS2 in Table 5 is used for PS1 and PS2, it would be possible to meet the head and flow requirements; however, the total cost would be EUR 50,334. That is, the cost would be $25 \%$ more expensive than that of the suggested implementation. In this way, if only the model selected for PS3 is used, the total cost would be EUR 70,980, which represents an increase of $76 \%$ compared to the cost of the best solution found. Similarly, the same comparison can be made for all combination options for the 67 models in the database.

The solution obtained indicates that the algorithm did not select any FSP. Although the implementation of VSPs is more expensive and incorporates the loss of efficiency introduced by frequency inverters, these pumps allow for the reduction of excessive energy 
consumption. Therefore, this turns into lower economic costs. Nevertheless, these results are not generalizable to all networks because the number of pumps in each of them depends on the conditions of each WDN and the current energy prices.

Despite the benefits of the work presented, it does present some limitations. In this work, the control system of pumps fits their heads to a calculated setpoint curve. VSPs are used first, and then FSPs are applied. Therefore, to extend the proposed model, it would be interesting to incorporate other control systems. Additionally, the calculation of OPEX is presented through a second-degree equation; however, the incorporation of a different exponent does not pose a major problem. That is, it does not affect the methodology presented.

\section{Conclusions}

The design of PSs in a WDN is a very complex and critical problem for any city. Water pumping operations represent a large fraction of the electrical power consumed in urban zones. The investment cost of each PS is very high and directly influences the future energy consumption of the overall network.

Traditionally, this type of design problem is solved by considering only the extreme consumption points or by optimizing the design and operation objectives in two independent stages. This approach does not allow for the capacity of the PS to be adapted to actual operating conditions. Therefore, excess energy is generated, so the costs of WDN grow significantly. To avoid this, a new methodology was proposed in this paper for the design of PSs in networks with multiple pumped water sources and no storage.

A mathematical optimization model was developed to simultaneously minimize the sum of the OPEX and CAPEX incurred by the network through the use of a setpoint curve. Based on the results obtained from the developed model, it is possible to determine the optimal selection of pump models from a database, the numbers of VSPs and FSPs, the lengths and diameters of the pipes, the distribution of flows, and the statuses of the pumps during each period.

A case study was presented, and the results obtained from the application of the PGA were satisfactory. The main benefits of using this new methodology are clearly demonstrable. The use of the setpoint curve ensured compliance with the requests made throughout the WDN and reduced energy excesses by reducing the differences between the consumption curves and the heads used by the pumps. Furthermore, the design of each PS considered the impact of that station on the entire network, including the effects on the rest of the PSs in the long term.

As discussed in the paper, the presented work has some limitations. Only one control system for the pumps is contemplated. That is, VSPs follow the setpoint head, while FSPs only have on/off states. However, the inclusion of new pump control methods does not require any change in the general methodology.

Author Contributions: All authors contributed extensively to the work presented in this paper. Conceptualization, J.H.G.-B., P.L.I.-R., and F.J.M.-S.; data curation, J.H.G.-B., Y.S., and F.J.M.-S.; formal analysis, J.H.G.-B., P.L.I.-R., and F.J.M.-S.; funding acquisition D.M.-M.; investigation, J.H.G.-B., P.L.I.-R., F.J.M.-S., and D.M.-M.; methodology J.H.G.-B., P.L.I.-R., F.J.M.-S., and D.M.-M.; project administration P.L.I.-R. and F.J.M.-S.; resources, J.H.G.-B., P.L.I.-R., F.J.M.-S., and D.M.-M.; software, J.H.G.-B., P.L.I.-R., Y.S., and F.J.M.-S.; supervision, P.L.I.-R. and D.M.-M.; validation, J.H.G.-B., P.L.I.-R., F.J.M.-S., Y.S., and D.M.-M.; visualization, J.H.G.-B., P.L.I.-R., F.J.M.-S., and D.M.-M.; writing-original draft, J.H.G.-B., P.L.I.-R., F.J.M.-S., and D.M.-M.; writing—review and editing, J.H.G.-B., P.L.I.-R., F.J.M.-S., and D.M.-M. All authors have read and agreed to the published version of the manuscript.

Funding: This research was funded by the Program Fondecyt Regular, grant number 1210410.

Institutional Review Board Statement: Not applicable.

Informed Consent Statement: Not applicable.

Data Availability Statement: Not applicable. 
Acknowledgments: This work was supported by the Program Fondecyt Regular (Project $\mathrm{N}^{\circ} 1210410$ ) of the Agencia Nacional de Investigación y Desarrollo (ANID), Chile. It is also supported by CONICYT PFCHA/DOCTORADO BECAS CHILE/2018-21182013.

Conflicts of Interest: The authors declare no conflict of interest.

\section{References}

1. Mala-Jetmarova, H.; Sultanova, N.; Savic, D. Lost in Optimisation of Water Distribution Systems? A Literature Review of System Design. Water 2018, 10, 307. [CrossRef]

2. Şen, Z. Water Structures and Climate Change Impact: A Review. Water Resour. Manag. 2020, 34, 4197-4216. [CrossRef]

3. Makaremi, Y.; Haghighi, A.; Ghafouri, H.R. Optimization of Pump Scheduling Program in Water Supply Systems Using a Self-Adaptive NSGA-II; a Review of Theory to Real Application. Water Resour. Manag. 2017, 31, 1283-1304. [CrossRef]

4. Gupta, A.; Kulat, K.D. A Selective Literature Review on Leak Management Techniques for Water Distribution System. Water Resour. Manag. 2018, 32, 3247-3269. [CrossRef]

5. Mala-Jetmarova, H.; Sultanova, N.; Savic, D. Lost in optimisation of water distribution systems? A literature review of system operation. Environ. Model. Softw. 2017, 93, 209-254. [CrossRef]

6. León-Celi, C.; Iglesias-Rey, P.L.; Martinez-Solano, F.J.; Mora-Melia, D. A Methodology for the Optimization of Flow Rate Injection to Looped Water Distribution Networks through Multiple Pumping Stations. Water 2016, 8, 575. [CrossRef]

7. Pulido-Calvo, I.; Gutiérrez-Estrada, J.C. Selection and operation of pumping stations of water distribution systems. Environ. Res. J. 2011, 5, 1-20.

8. Blinco, L.J.; Simpson, A.R.; Lambert, M.F.; Marchi, A. Comparison of Pumping Regimes for Water Distribution Systems to Minimize Cost and Greenhouse Gases. J. Water Resour. Plan. Manag. 2016, 142, 04016010. [CrossRef]

9. Carpitella, S.; Brentan, B.; Montalvo, I.; Izquierdo, J.; Certa, A. Multi-criteria analysis applied to multi-objective optimal pump scheduling in water systems. Water Supply 2019, 19, 2338-2346. [CrossRef]

10. Müller, T.M.; Leise, P.; Lorenz, I.-S.; Altherr, L.C.; Pelz, P.F. Optimization and validation of pumping system design and operation for water supply in high-rise buildings. Optim. Eng. 2021, 22, 643-686. [CrossRef]

11. Martin-Candilejo, A.; Santillán, D.; Iglesias, A.; Garrote, L. Optimization of the Design of Water Distribution Systems for Variable Pumping Flow Rates. Water 2020, 12, 359. [CrossRef]

12. Nguyen, K.D.; Dai, P.D.; Vu, D.Q.; Cuong, B.M.; Tuyen, V.P.; Li, P. A MINLP Model for Optimal Localization of Pumps as Turbines in Water Distribution Systems Considering Power Generation Constraints. Water 2020, 12, 1979. [CrossRef]

13. Nagkoulis, N.; Katsifarakis, K. Minimization of Total Pumping Cost from an Aquifer to a Water Tank, Via a Pipe Network. Water Resour. Manag. 2020, 34, 4147-4162. [CrossRef]

14. Fecarotta, O.; McNabola, A. Optimal Location of Pump as Turbines (PATs) in Water Distribution Networks to Recover Energy and Reduce Leakage. Water Resour. Manag. 2017, 31, 5043-5059. [CrossRef]

15. Shao, Y.; Yu, Y.; Yu, T.; Chu, S.; Liu, X. Leakage Control and Energy Consumption Optimization in the Water Distribution Network Based on Joint Scheduling of Pumps and Valves. Energies 2019, 12, 2969. [CrossRef]

16. Weber, J.B.; Lorenz, U. Optimizing booster stations. In Proceedings of the Genetic and Evolutionary Computation Conference Companion; ACM Press: New York, NY, USA, 2017; pp. 1303-1310.

17. Kang, D.; Lansey, K. Scenario-Based Robust Optimization of Regional Water and Wastewater Infrastructure. J. Water Resour. Plan. Manag. 2013, 139, 325-338. [CrossRef]

18. León-Celi, C.F.; Iglesias-Rey, P.L.; Martínez-Solano, F.J.; Savic, D. Operation of Multiple Pumped-Water Sources with No Storage. J. Water Resour. Plan. Manag. 2018, 144, 04018050. [CrossRef]

19. Gil, F.A.A.; Iglesias-Rey, P.L.; Martínez-Solano, F.J.; Cortes, J.V.L.; Mora-Meliá, D. Methodology For Projects Of Pumping Stations Directly Connected To The Network Considering The Operation Strategy. Int. Congr. Proj. Manag. Eng. 2018, 2-018, 551-563.

20. Mora-Melia, D.; Iglesias-Rey, P.L.; Martinez-Solano, F.J.; Fuertes-Miquel, V.S. Design of Water Distribution Networks using a Pseudo-Genetic Algorithm and Sensitivity of Genetic Operators. Water Resour. Manag. 2013, 27, 4149-4162. [CrossRef]

21. Turci, L.D.O.; Wang, J.; Brahmia, I. Adaptive and Improved Multi-population Based Nature-inspired Optimization Algorithms for Water Pump Station Scheduling. Water Resour. Manag. 2020, 34, 2869-2885. [CrossRef]

22. Gutiérrez-Bahamondes, J.H.; Salgueiro, Y.; Silva-Rubio, S.A.; Alsina, M.A.; Mora-Meliá, D.; Fuertes-Miquel, V.S. jHawanet: An Open-Source Project for the Implementation and Assessment of Multi-Objective Evolutionary Algorithms on Water Distribution Networks. Water 2019, 11, 2018. [CrossRef]

23. Rossman, L.A. EPANET 2.0 User's Manual (EPA/600/R-00/057); Water Supply and Water Resources Division, National Risk Management Research Laboratory: Cincinnatti, OH, USA, 2000.

24. Mora-Melia, D.; Iglesias-Rey, P.L.; Martinez-Solano, F.J.; Ballesteros-Pérez, P. Efficiency of Evolutionary Algorithms in Water Network Pipe Sizing. Water Resour. Manag. 2015, 29, 4817-4831. [CrossRef]

25. Mora-Melià, D.; Martínez-Solano, F.J.; Iglesias-Rey, P.L.; Gutiérrez-Bahamondes, J.H. Population Size Influence on the Efficiency of Evolutionary Algorithms to Design Water Networks. Procedia Eng. 2017, 186, 341-348. [CrossRef]

26. Mora-Melià, D.; Iglesias-Rey, P.L.; Fuertes-Miquel, V.S.; Martinez-Solano, F. Comparison of Evolutionary Algorithms for Design of Sewer Systems; CRC Press: Boca Raton, FL, USA, 2009; Volume 1, pp. 261-263. 